\title{
The influence of money attitude, financial practices, self-efficacy and emotion coping on employ- ees' financial well-being
}

\author{
Mohamad Fazli Sabri ${ }^{a^{*}}$, Rusitha Wijekoon ${ }^{b}$ and Husniyah Abd Rahim ${ }^{\mathrm{c}}$
}

${ }^{a}$ Department of Resource Management \& Consumer Studies, Faculty of Human Ecology, Universiti Putra Malaysia, 43400 UPM Serdang, Selangor, Malaysia

${ }^{b}$ Technology Transfer Division, Coconut Research Institute of Sri Lanka, Lunuwila, 61150, Sri Lanka

${ }^{c}$ Department of Resource Management \& Consumer Studies, Faculty of Human Ecology, Universiti Putra Malaysia, 43400 UPM Serdang, Selangor, Malaysia

\section{CH R O N I C L E}

\section{Article history:}

Received: September 82019

Received in revised format: Sep-

tember 222019

Accepted: October 6, 2019

Available online:

October 6, 2019

Keywords:

Emotion coping

Financial practices

Financial well-being (FWB)

Financial wellness

Money attitude

Self-efficacy

\begin{abstract}
A B S T R A C T
Financial Stability and Payment Systems Report of the Bank Negara Malaysia reported that household debt grew by $5.4 \%$ to RM1.09 trillion from a year earlier. Notably, households merely borrow or use credit for purchasing in order to smoothen their consumption. Less secure and vulnerable current, and retirement stages would be the result among public employees in Malaysia due to high household debts. Enhancing trend of better financial management practices is essential, especially for working employees due to the increased levels of existing personal indebtedness, and increasing focus on personal responsibility for financial planning among them. Nowadays, employee's role in managing their finances is becoming complex due to experiencing with the complexity of financial commodities in the marketplace. Therefore, studying of the determinants of employees' financial well-being (FWB) among employees in Malaysia is the major objective of this research. The sample of 590 employees in the public sector from four states was selected by applying multi stage sampling technique. The data gathering was accomplished using a self-administered questionnaire. According to the regression analysis, contribution of the variables to the model was $32.3 \%$. Money attitude, financial practices, self-efficacy, and emotion coping had conspicuous contribution to FWB, while financial practices were identified as the key performing aspect to FWB. The findings of this study are beneficial to the government, and NonGovernmental Organizations (NGOs) to create a comprehensive approach specially to advance the living standards, and enhance the FWB of the lower-household income cluster of employees. More comprehension about the determinants of FWB plays a vital role to support workers to equip with financial prudence, and in the longrun would minimize the rate of Malaysian workers with financial difficulties.
\end{abstract}

\section{Introduction}

Financial well-being (FWB) has recently gained an expanding consideration by scientists, and researchers from various fields. Endeavours have been made to explain a vision of the FWB, and distinguish what contributes to FWB or wellness. Shim et al., (2009) characterize FWB as gratification with individual's existing economic standing, and level of debt. As per Joo (2008), FWB is a sensation of being financially strong, pleased, and free from worry, and is generally established on an emotional examination of a person's budgetary circumstance. But, van Praag et al. (2003) describe FWB as overall satisfaction with individual's financial state. Joining of two phrases, finance, and well-being lessens one of the greatest hindrances to individuals concentrating on the finances, that is the tendency to think about monetary matters as independent from or disconnected to the different components of lifecycle. FWB is a significant influence in deciding one's personal satisfaction. From a person's perspective, FWB is significant, and studies have demonstrated that there is a solid, and constructive connection to overall well-being of a person. van Praag et al. (2003), stated that a wise expenditure pattern, and savings account balance are critical factors for affecting personal well-being. Moreover, they influence the mental, and physical wellbeing of employees, and enhance the efficiency in the work environment by fortifying the duties in their occupations. However, an imbalance in FWB among employees could adversely influence for the organizational efficiency. Employees

* Corresponding author. Tel: +603-89467054, Fax: 603-89467899

E-mail address: fazli@upm.edu.my (M. F. Sabri) 
who are financially unhealthy are regularly stressed, and distracted, affecting absenteeism, efficiency, retirement, and medicinal services costs. In this manner, employee well-being is a critical factor that organizations are endeavouring to deliver to guarantee that their staff stay happy, and motivated at work. All things considered, a happy workforce means not only a productive workforce, but also a productive work place. Furthermore, employees of exchanging companies are probably going to drop revenue, and non-financial advantages of working for the company, which makes bankruptcy costly for workers. Bankruptcy is a legal process via which individuals who cannot reimburse obligations to lenders may look for help from few or the majority of debts. In most jurisdictions, bankruptcy is forced by a court order, regularly started by the indebted person. Organizations with an enthusiasm for employee's well-being are in this manner prone to diminish the opportunity of bankruptcy, contrasted with companies with lower interests in employee well-being. Since bankruptcy happens when companies cannot satisfy their debt payments, an undeniable method for diminishing the likelihood of financial distress is diminishing the company's influence. Moreover, abnormal state of employee well-being, is related with a lower debt-assets ratio (Verwijmerena \& Derwall, 2010).

A few Malaysians aged between 18 to 44 years of age have been declared bankrupt in the course of the most recent five years. The most elevated instances of bankruptcy among the adolescent were recorded in 2014 with a sum of 13,098 cases, trailed by 13,036 cases in 2013, in view of the measurements from the Insolvency Department (The Star, 2018). This issue can be overwhelmed by distinguishing potential bankrupts, and the variables that are related with them. Few people fall bankrupt because of poor discipline, and inability to deal with their accounts. Most instances of bankruptcy are not brought about by irresponsible expenditure yet by financial hardship, and many are less income people who essentially cannot bear to manage unforeseen major costs, for example, losing of the job or hospital expenses. Employers could consider debt consolidation choices, for example, debt managing strategies, debt consolidation loans, and debt settlement, a choice to elude bankruptcy. Academics have detailed that various factors have all the earmarks of being reliably connected with FWB. The most widely recognized parameters are demographic, and socioeconomic features for example, age, gender, ethnicity, education, marital status, and income (Hira \& Mugenda, 1999). While FWB is fundamentally identified to relate with some demographic factors, other parameters for example, money attitude (Nickerson et al., 2007; Sabri \& Zakaria, 2015a; 2015b; Shim et al., 2009; Arendt \& Brettel, 2010), financial practices (O’Neill et al., 2005), emotion coping (Por et al., 2011), and self-efficacy (Farrell et al., 2016) can likewise influence FWB. Therefore, studying of the determinants of FWB among employees in central region, Peninsular Malaysia is the major objective of this research.

\subsection{Financial well-being}

The attention for FWB is rising in numerous nations. The emphasis is prevalently on parameters prompting expanded wellbeing among the inhabitants, and the policy measures to accomplish it. The large portion of studies has considered the general FWB of inhabitants, instead of the less attention on negative well-being effects, for example, deficiency, financial strain or payment difficulties (Mack \& Lansley, 1985). Despite the fact that, various studies have been attempted to quantify the dimension of general FWB in people in various nations, the vast majority of them depend on personal measures, applying the compositions on common health, and well-being. However, no proper definition or strategy for estimation, and questionnaire content has generally been established normatively. There is an assorted variety of existing meanings of FWB, and most have been inferred hypothetically. But, the given definition for the FWB by Consumer Financial Protection Bureau (CFPB; 2015) is;

"A state wherein a person can fully meet current and ongoing financial obligations, can feel secure in their financial future, and is able to make choices that allow enjoyment of life".

FWB joins with the ideas linked to the arenas of individual finance, and the more extensive zone of individual well-being. Both parameters have developed in parallel, and share some various common characteristics such as, economics, psychology, and health (Bowman et al., 2016). The most deliberate work of the possible associations among FWB, and financial knowledge, literacy, financial capability, and personality traits which was commenced by the CFPB (2015) is qualitative. They have discussed every one of these three zones in discussions with both customers, and financial consultants to recognize their perceiving ability to emphasize FWB, and their comparative significance. When considering about performances initially, the ones referenced in the discussions have been classified into four clusters: efficient repetitive monetary management; efficient financial investigation, \& information pursuing; financial design, \& goal setting, and following through on financial conclusions. According to the effect on behaviours, the indirect effect was revealed as knowledge, skills, and personality qualities. Away from these characteristics of a person, the social, and economic environment was likewise taken into account to assume a vital role in deciding FWB (CFPB, 2015). Uplifting the personal wellbeing has turned a significant strategy need in numerous nations. These requirements driven scholars to prioritize understanding it, estimating it, and investigating approaches to best develop the traits that guide to well-being. Academics have detailed that various factors have all the earmarks of being reliably connected with FWB. The most widely recognized parameters are demographic, and socioeconomic features for example, age, gender, ethnicity, education, marital status, and income (Hira \& Mugenda, 1999). While FWB is fundamentally identified to relate with some demographic factors, other parameters for example, money attitude (Nickerson et al., 2007; Sabri \& Zakaria, 2015a; 2015b; Shim et al., 2009), financial practices (O’Neill et al., 2005; Vlachos et al., 2009), emotion coping (Por et al., 2011), and self-efficacy (Farrell et al., 2016) can likewise influence FWB. 


\subsubsection{Gender differences in FWB}

In their review, Leach et al. (1999) specified the studies which show the effect of gender differences regarding financial matters such as credit, and spending behavioural studies. In Malaysia, few researchers (Falahati \& Sabri, 2015; Kamaruddin \& Mokhlis, 2003; Masud et al., 2004; Sabri et al., 2010) have studied gender differences in FWB. When considering satisfaction measures, Theodos et al. (2014) found that women, and men do not have differential rates of satisfaction with their personal financial conditions (assets, debts, and savings) which directly affect their FWB. Therefore, we can develop a hypothesis;

$\mathrm{H}_{1}$ : A significant difference exists in FWB between male, and female employees.

\subsubsection{Marital status differences in FWB}

According to Godwin (1996), the money management, actual money managing behaviours, and perceptions of income adequacy were identified as intervening variables between "financial and marital well-being". While, Gray (1997), stated that the married people are more dynamic than unmarried people, and therefore achieve better FWB (Gray, 1997). Further, according to Korenman and Neumark (1991), better performance ratings were gained by married males than single males, hence it has direct relationship towards their FWB. Furthermore, a statistically noteworthy difference between the FWB, and marital status (married and single) of Malaysian young employees were identified by Sabri and Zakaria (2015a). Therefore, the formulated hypothesis is;

$\mathrm{H}_{2}$ : A significant difference exists in FWB between married, and single employees.

\subsubsection{Income group differences in FWB}

A positive association between subjective financial well-being (SFWB), and income group of households was observed by Mahdzan et al. (2019) in the study which was conducted in Malaysia to find out the determinants of SFWB across three different household income groups. Further, several previous studies were given evidences for a significant effect of income on SFWB (e.g. Doyle \& Forehand, 1984; George, 1992; Headey et al., 1991; La Barbera \& Gürhan, 1997). Even though, lots of researches revealed a positive bivariate relationship between SFWB, and income, the relationship between income, and SFWB was not as much of obvious in a multivariate framework (George, 1992). Whereas, Diener et al. (1995), and Veenhoven (1991) suggested that the lack of income would lead to low SFWB, and the relationship between income, and SFWB was not a positive linear one. Furthermore, according to the study on young employees of Malaysia, a statistically noteworthy variance was found between the FWB, and different household income groups (Sabri \& Zakaria, 2015a). Therefore, based on above direct and indirect evidences, we formulate the following hypothesis;

$\mathrm{H}_{3}$ : A significant difference exists in FWB between low, medium, and high-income group of employees.

\subsubsection{Money attitude and FWB}

Money attitude is a type of person's behaviour as assessment results to exclusive advantages of, a function, and the emblematic importance of cash can influence on purchasing behaviour (Kristanto, 2011). Qamar et al. (2016) express that money attitude is one's discernment about money. An individual characterizes money as a tool that can influence on activities in the administration of money. Indeed, one's money attitudes will impact their practices when they are shopping, and saving, and lastly is heading off with an impact the accomplishment of certain life goals (Nga \& Yeoh, 2015). With fruitful life goals, individuals gain life fulfilment, and Nickerson et al. (2007) endeavoured to support the connection between life satisfaction, and FWB. Moreover, a positive association was detected by Falahati and Paim (2011) in their study on money attitude among university students. Particularly in recent years, various studies in the area of economic psychology observed individual's beliefs or attitudes about money. According to the cross-sectional investigations, there is a positive association between money attitude, and FWB (Gasiorowska, 2015). Therefore, we can develop a hypothesis in the accompanying manner.

$\mathrm{H}_{4}$ : A significant difference exists between employees' money attitude and FWB.

\subsubsection{Financial practices and FWB}

The terminology, financial practices alludes to the arrangement of regular techniques or standard working methods that construct for completing accounting, money related detailing, budgeting, and different exercises identified with business finances. The better financial practices of financially bothered consumers were assumed a significant job to enhance their health, and FWB dimensions by diminishing financial distress (O'Neill et al., 2005). Financial practice is one of the functional factors of FWB (Kim et al., 2003). Evolving positive financial practices during the school years expands a person's chances of accomplishing a superior life later (Worthy et al., 2010; Xiao et al., 2009). Therefore, the formulated hypothesis would be;

$\mathrm{H}_{5}$ : A significant difference exists between employees’ financial practices and FWB.

\subsubsection{Self-efficacy and FWB}

Customers having high dimensions of perceived financial self-efficacy are certain about their capacities to acquire data to settle on financial decisions, positive about their capacity to take intelligent choices, and self-controlled with finances. The 
self-efficacy prompts an evasion of financial anxiety, and negative financial behaviours that accompanies with them (Hadar et al., 2013). The self-efficacy may help reactions unpleasant present circumstances by encouraging customers inspired to address difficulties (Kammeyer-Mueller et al., 2009). Further, Xiao et al. (2011) observed that financial efficacy has an indirect positive association with financial satisfaction, and FWB. Along these lines, a positive correlation could be identified between self-efficacy, and the FWB. The research by Farrell and Risse (2016) reveals the association of financial self-efficacy on women's personal FWB using an econometric model and financial self-efficacy thrives to clarify its job towards personal financial behaviour. Further, past studies show that financial efficacy had a positive association with FWB (Shim et al., 2009). Therefore, a hypothesis was derived in the following way.

$\mathrm{H}_{6}$ : A significant difference exists between employees' self-efficacy and FWB.

\subsubsection{Emotion coping and FWB}

It was observed that adapting procedures may diminish the impact on FWB (Lazarus \& Folkman, 1984). Adapting procedures have frequently been arranged into two general classifications: problem, and emotion focused approaches. Issue cantered methodologies employed behavioural events, for example, action and planning, while emotion-focused approaches included fluctuating expectations, and expressing emotion. Besides, the investigation of Por et al. (2011) gives some intriguing starter discoveries which recommend that emotional competence, and an expanded sentiment of control help student nurses embrace an effective, and functioning adapting system to manage pressure, which thusly improves their well-being. The literature on coping by and large demonstrates that females utilize more emotion-focused coping than males (Lazarus \& Folkman, 1984). While et al. (2005) have discovered that, emotional coping is ventured to intervene the impacts of burden on the well-being. Some scholars suggested that coping strategies could be diminished the impact of pressure on FWB (Lazarus \& Folkman 1984). With the study of schoolchildren utilization of emotion coping approaches, especially the utilization of coping escaping plans was related with negative results, for example, expanded negative affect, and poorer health (Pritchard et al., 2007). Conversely, some emotion coping approaches for example, acknowledgment, and positive reframing are linking with better well-being (Scheier et al., 1994). Therefore, a hypothesis was derived as follows.

$\mathrm{H}_{7}$ : A significant difference exists between employees' emotion coping and FWB.

\subsubsection{Determinants of FWB}

The significant relationships between FWB, and type of money attitude, financial literacy, financial capability, and financial strain were revealed by Sabri and Zakaria (2015) in their study with Malaysian young employees. Based on the results of Siu et al. (2007), an association was revealed between general self-efficacy, and employees' FWB. Sohn et al. (2012) studied the significant variables related to Korean high school students' financial knowledge, and well-being, and found that the most important one was attitudes towards money. Joo, and Grable (2004) pointed out that financial practices, for example, maintaining a weekly or monthly budget, setting money aside for saving, and paying credit card bills in full each month were linked with FWB, both directly, and indirectly. Additionally, Xiao et al. (2007) studied financial behaviour, and possible impacts of financial behaviours on the well-being of university undergraduates, and revealed that positive money managing, credit managing, and saving behaviours were positively correlated to overall well-being. Furthermore, the results of Scheier et al., (1994) reported that some emotion-coping strategies will be contributed to increased well-being levels of undergraduates. Therefore, considering the reviewed literature above the following hypotheses is derived;

$\mathrm{H}_{8}$ : Money attitude, financial practices, self-efficacy, and emotion coping are significant determinants of employees’ FWB.

\subsection{Theories and study framework}

In this research we suggest a conceptual model as an approach to look at the impact of financial practices, money attitude, emotion coping, and self-efficacy on employees' FWB. Employees' financial practices, money attitude, emotion coping, and self-efficacy are at that point, we set, connected to their FWB, which thusly is connected to their overall life success. The suggested conceptual model was established based on an interdisciplinary methodology that incorporates three prominent theories; the Well-being Theory (Seligman, 2011); Self-Efficacy Theory (Bandura, 1977), and Permanent Income Hypothesis (Friedman,1957).

\subsubsection{Well-being Theory (WBT)}

As per the Well-being Theory there are five structure obstructs that support to well-being of an individual; positive emotion, engagement, relationships, meaning, and accomplishment (PERMA), and having some strategies to expand them (Seligman, 2011). Various individuals will derive well-being from these five building blocks to different degrees. A decent life for one individual is not really a decent life for another. Concentrating on positive emotions is the capacity to stay optimistic, and see one's past, present, and future from a productive point of view. This sort of constructive emotion is crucial, and help individuals appreciate the everyday tasks in their lives, and continue on with difficulties they will face by staying hopeful about possible results. The second construct, engagement is an involvement wherein somebody completely organizes their skills, strengths, and consideration for a thought-provoking mission. Relationships, the third construct, are crucial to wellbeing. The encounters that add to well-being are regularly intensified via the affairs, for instance, incredible satisfaction, meaning, laughter, a sentiment of belonging, and pride in achievement. Research demonstrates that doing demonstrations of 
kindness for others delivers an expansion in well-being. Developing solid connections is integral to conversion, and is empowered by individual's ability for love, sympathy, kindness, teamwork, responsiveness, self-sacrifice, cooperation, and so on. The fourth building block, a sense of meaning, and purpose, could be resulted from belonging to, and offering an option that is greater than oneself. Different organizations are available in the society that empower a feeling of meaning, for example, family, religion, science, work organizations, politics, justice, social causes, the community among others. Individuals seek after accomplishment, competence, achievement, and dominance for the good of its own, in an assortment of domains, comprising the working environment, sports, games, interests, and so forth. Moreover, they pursue accomplishment, the final construct of the theory, notwithstanding when it does not really prompt to meaning, relationships, or positive emotion.

\subsubsection{Self-efficacy Theory (SET)}

According to the Bandura's SET, the beliefs become an essential, explicit clarification for inspiration (Bandura, 1977, 1986, 1997). In other words, the belief that people are fit for doing a particular undertaking or of achieving a particular goal is called self-efficacy. This belief, explicit to a task or a subject matter or performance, shapes the practices, and systems that help one seek after their goal. Bandura (1977) characterizes self-efficacy as an individual discernment of "how well one can execute courses of action required to deal with prospective situations". Self-efficacy beliefs have demonstrated to be steady indicators of behavioural outcomes, for example, performance (Ouweneel et al., 2013). People having high self-efficacy may apply satisfactory exertion that, if well implemented, prompts effective results, while people with little self-efficacy will be undoubtedly going to discontinue effort early, and be unsuccessful (Stajkovic \& Luthans, 1998).

\subsubsection{Permanent Income Hypothesis (PIH)}

The PIH (Friedman,1957) is an economic theory that defines how operators spread utilization over someone's lifetime. According to Friedman (1957), an individual's utilization at a point in time is determined not just by his/her current income as well as by his/her predictable income in forthcoming years called "permanent income". In its most straightforward structure, the PIH mentioned that fluctuations in permanent income, rather than variations in temporary income, are causing adjustments with in the customer's utilization patterns. It has profoundly affected the investigation of consumer behaviour, and gives a clarification to a portion of the disappointments of Keynesian demand management techniques (Meghir, 2004). For instance, an employee will save just if his or her current income is higher than the foreseen dimension of permanent income, to prepare against future failures in income.

\subsection{Study framework}

According to the literature of the theories discussed above, the theoretical framework for the study can be conceptualized in a model form as follows:

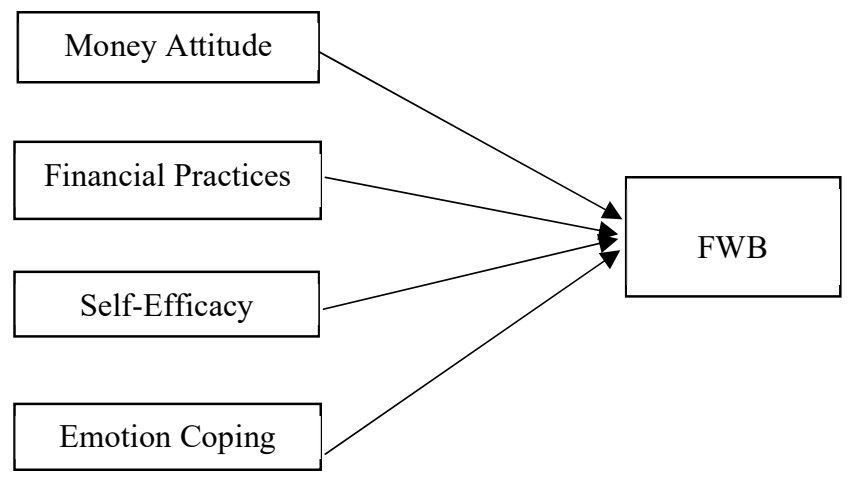

Fig. 1. Theoretical framework

The theoretical framework of this study was derived using three theories; SET, WBT, and PIH.

Bandura's SET (1977), defines self-efficacy as "the belief in one's effectiveness in performing specific tasks" (p.195), and in the Vosloo et al.'s study (Vosloo et al., 2014) it is inferred as "a person's satisfaction with confidence in his/her level of financial knowledge, and his/her ability to meet financial objectives" (p.1457). Furthermore, an individual's financial ability, and financial literacy are the two factors which influence the financial efficacy (Fox \& Bartholomae, 2008); hence, better financial efficacy leads to increased FWB (Vosloo et al., 2014). Higher FWB is one of the major goals of an employee, and increased self-efficacy is important to achieve the goal. Therefore, Bandura's SET (1977) was supported to construct the theoretical framework of this study. According to the WBT there are five different constructs; positive emotion, engagement, relationships, meaning, and accomplishment (PERMA) are affecting for the overall well-being of an individual (Seligman, 2011). One of the important aspects of the overall well-being is FWB, and therefore, this study assumed that the factors 
which are important to overall well-being also influence on FWB of Malaysian employees. The PIH (Friedman,1957) describes, individual's utilization patterns are completely depend on mostly due to the variations in permanent income, rather than fluctuations in temporary income. Therefore, personal FWB was affected by individual's various utilization patterns. The money attitude, financial practices, self-efficacy, and emotion coping strategies are some of the significant factors that effect on FWB, and hence, PIH was used as one of the supportive hypotheses of the theoretical framework.

\section{Research Methodology}

According to the findings of Faruqi (2011), Malaysia is a country with the maximum ratio of public employees to population in the world, which creates the attention on employees, and therefore, the respondents were selected from the government sector for this study. Four states were randomly selected for this research study. From each state, five government agencies were randomly selected. Thus, each government agencies required 30 respondents to take part in this study. The sample of study was selected from the area of Peninsular Malaysia using multi-stage random sampling technique. First of all, Peninsular Malaysia was grouped into four regions, namely North (Kedah, Perlis, Penang), South (Melaka, Johor, Negeri Sembilan), East (Pahang, Terengganu, Kelantan), and West (Selangor, Perak, Wilayah Persekutuan). Secondly, through ballot procedure, one state was randomly chosen from each zone. As the result, the selected sampling areas were; Penang (North), Johor (South), Terengganu (East), and Perak (West). As suggested by sample size calculation, the present study required 384 respondents. However, 600 of respondents were selected to compensate for lost, and unreturned questionnaires, and uncooperative respondents. Thus, a total of 150 respondents were obtained from each state, respectively. Upon conformed the locations, a list of all government agencies located in the selected areas was attained from the official portal. Then, five government agencies were randomly selected from each location through ballot. Lastly, 30 respondents were randomly selected from each agency. The final sample size of this research was 590 employees with the response rate of $98.3 \%$.

\subsection{Instrumentation}

Generally, the questionnaire was grouped into six segments. Segment A consists of demographic and socioeconomic background information. Section B asks about the respondents' money attitude, while section C comprises questions on financial practices. Moreover, section D and E inquire about the respondents' self-efficacy, and emotion coping, whereas section $\mathrm{F}$ pertains to FWB.

\subsection{Respondent's profile}

Related questions of respondents' socio-demographic background information are contained in the section A for example, age, gender, educational attainment, ethnicity, monthly salary, marital status, household size, home ownership status, percentage of monthly savings as compared to income and current financial status.

\subsection{Money attitude}

Section B of the questionnaire contains 24 questions about money attitudes. Employees' money attitude will be measured using an instrument with five-point Likert scale ranging from $1=$ strongly not agree to $5=$ strongly agree, adopted from Furnham (1984). Respondents were required to answer the questionnaire based on their attitude pertaining to each given statement.

\subsection{Financial practices}

Third part of the questionnaire, section $\mathrm{C}$, was important to gather the data of the respondents' financial practices. Financial practices will be measured using an instrument adopted from Sabri et al., (2010). Three-point Likert scale; $1=$ not sure, $2=$ sometimes, and 3 = always was applied to evaluate financial exercises of selected employees including retirement planning, budgeting, estate planning, make financial goals, and discipline in spending.

\subsection{Self-efficacy}

Fourth part of the questionnaire, section D, was used to gather the data of respondents' self-efficacy. This section was utilized the New General Self-Efficacy Scale which was adopted by Chen et al. (2001). The responses were assessed using the fivepoint Likert scale.

\subsection{Emotion coping}

Section E consists of five items concerning on various emotion strategies related to achieved financial security. The instrument was applied to measure the behavioural feedback of respondents especially in the situations of worried about finances or short of money. Caplan, and Schooler's (2007) emotion coping mechanism item with five-point Likert scale was recruited to gather the data.

\subsection{Financial well-being}

In this section, 12 items were used to gather information on FWB. The employees' FWB was gathered by an instrument adopted from Anderloni et al. (2012). Employees were necessary to give their responses for the queries based on their perceptions of financial stability or security on each given each statement with five-point Likert scale. 


\subsection{Analysis of the data}

The gathered information was analysed using the Statistical Package for the Social Science (SPSS) Software version 13. In this section, the statistical procedures for the descriptive analysis of the socio-demographic characteristics, independent, and dependent variables are described. In addition, inferential statistical analysis, including Pearson's correlation, T-test, Anova, and multivariate analysis are discussed as well.

\section{Results and Discussion}

\subsection{Respondents' profile}

In terms of gender, $52 \%$ of the participants were female, and the remaining balance were male. More than half $(52.9 \%)$ of the respondents in the age between 30-39 years old, and more than two-third were married (71.6\%). Majority of the participants were Malay $(92.6 \%)$, and trailed by Chinese $(2.7 \%)$, Indian $(2.2 \%)$, and others $(2.4 \%)$. In terms of education, about half of the respondents had a tertiary level of education from either university or college. The result displays that higher percentage of the respondents had monthly incomes less than RM3,000.

\subsection{Bivariate results}

$\mathrm{H}_{1}$ : A significant difference exists in FWB between male, and female employees.

Table 1

Comparison of gender for FWB

\begin{tabular}{lccccc}
\hline Gender & $\mathrm{N}$ & Mean & SD & $t$ & Sig. \\
\hline Male & 235 & 94.0553 & 22.85 & -1.673 & 0.933 \\
Female & 320 & 97.3500 & 22.98 & & \\
\hline \multicolumn{2}{c}{ *Significant $\mathrm{p}<0.05$} & & & &
\end{tabular}

The FWB scores for male, and female employees were analysed using independent sample t-test, and the results are shown in the Table 1. A noteworthy difference in scores for male $(\mathrm{M}=94.05, \mathrm{SD}=22.85)$, and female workers $(\mathrm{M}=97.35, \mathrm{SD}=22.98 ; t$ $(508)=-1.67, \mathrm{p}=0.933)$ could be seen. Even though, female mean scores were greater than male, no significant difference between male, and female workers were shown. This gender-based could not be expected to have an effect on financial practices. Gender has not been reliably identified with FWB whereby a few researchers have observed that females are expected to be more FWB than male (Lea et al., 1995), while Boddington, and Kemp (1999) have revealed that male are more FWB than female, but the outcome demonstrated that both females, and males will in general be similarly FWB. Therefore, the hypothesis was rejected.

$\mathrm{H}_{2}$ : A significant difference exists in FWB between married, and single employees.

Table 2

Comparison of marital status for FWB

\begin{tabular}{lccccc}
\hline Marital status & $\mathrm{N}$ & Mean & SD & $t$ & Sig. \\
\hline Married & 160 & 91.8500 & 23.28 & 2.611 & 0.009 \\
Single & 394 & 97.5000 & 22.56 & & \\
\hline \multicolumn{1}{c}{${ }^{* \text { Significant } \mathrm{p}<0.05}$} & & & & & \\
\hline
\end{tabular}

The FWB scores for married, and unmarried employees were analysed using independent sample t-test, and results are shown in Table 2. A noteworthy difference in scores for married $(\mathrm{M}=91.85, \mathrm{SD}=23.28)$, and unmarried employees $(\mathrm{M}=97.50$, $\mathrm{SD}=22.56 ; t(554)=2.611, \mathrm{p}=0.009)$ could be seen. Hence, a significant difference could be identified between married, and unmarried workers. Married employees will in general be more financially healthy contrasted with the single workers. As indicated by Sweeney (2002), economic well-being is increased with the marriage. Married couples ordinarily deal with their assets together accordingly enabling them to acclimate to the economic environments contrasted with the non-married employee (Brines \& Joyner, 1999). According to the survey conducted by Met life Study of Family Structure, and FWB in USA married people $(\mathrm{M}=14.91, \mathrm{SD}=2.31)$ had a strong causal relationship toward FWB contrasted with never married or single individual $(\mathrm{M}=14.06, \mathrm{SD}=2.53)$ whereby the mean difference was 14.61 at 0.001 significant level. It was found that the shared support, and household roles play a vital role for married couples to enhance their FWB. Therefore, the hypothesis was accepted.

$\mathrm{H}_{3}$ : A significant difference exists in FWB between low, medium, and high-income group of employees.

Table 3

Comparison of income group for FWB

\begin{tabular}{lccccc}
\hline Income group & $\mathrm{n}$ & Mean & SD & F & $\mathrm{p}$ \\
\hline Low & 236 & 88.1525 & 21.60 & 34.348 & 0.000 \\
Middle & 191 & 98.9162 & 21.63 & & \\
High & 120 & 107.5500 & 21.69 & & \\
\hline \hline
\end{tabular}


The investigations of the FWB among three income groups; low, middle, and high (Group 1: less than RM1, 500; Group 2: RM1, 500 to RM3, 500; Group 3: Above RM3, 500) were done using the one-way analysis of variance. Income groups were identified based on grouping system of monthly family income applied in $10^{\text {th }}$ Malaysian Plan. A statistically significant difference in FWB for the three income groups were identified at the $\mathrm{p}<0.05$ level $(\mathrm{F}(483)=34.348, \mathrm{p}=0.000)$, and the results are shown in the Table 3. The Tukey HSD test was performed to conduct post-hoc comparisons, and according to the results, the mean score for Group $1(\mathrm{M}=88.1525, \mathrm{SD}=21.60)$, and Group $2(\mathrm{M}=98.9162, \mathrm{SD}=21.63)$ were significantly different from Group $3(\mathrm{M}=107.55, \mathrm{SD}=21.69)$. Whereas, Group $2(\mathrm{M}=98.9162, \mathrm{SD}=21.63)$ was not different significantly from Group 1 $(\mathrm{M}=88.1525, \mathrm{SD}=21.60)$. It demonstrates that the employees belong to high-income category were more financially contrasted comparing with other groups. House hold income afford individuals to address their issues whereby individuals with more prominent wages are more likely to be able to address their issues, for example, safety measures, healthy food, comfortable housing, and health that direct to the better subjective FWB contrasted with the poorer livelihoods. The higher well-being was evidenced in the study of Diener, and Oishi (2000) which was conducted in South Korea, Japan, Singapore, and China, with increased individual's income. Therefore, the hypothesis was accepted.

Table 4

Pearson's Correlation Coefficients between money attitude, financial practices, self-efficacy, and emotion coping with FWB

\begin{tabular}{lcc}
\multicolumn{1}{c}{ Variables } & Pearson Correlation $(r)$ & $p$ \\
\hline Money attitude & $0.472 * *$ & 0.000 \\
Financial practices & $0.414 * *$ & 0.000 \\
Self-efficacy & $0.397 * *$ & 0.000 \\
Emotion coping & $-0.091 *$ & 0.034 \\
\hline \multicolumn{1}{c}{ Significant: ${ }^{*}{ }^{*} p<0.01 ;{ }^{*} p<0.05$} & &
\end{tabular}

$\mathrm{H}_{4}$ : A significant difference exists between employees' money attitude and FWB.

Pearson's Correlation Coefficient was utilized to study whether there is a connection between money attitude, and FWB of workers. A positive relationship was identified according to the Pearson's Correlation results in Table 4 between money attitude, and FWB $(r=0.472, n=554, p=0.000)$, which is fitted to the research hypothesis. More elevated levels of money attitude were related with more prominent dimensions of FWB. Previous research has also proved that distinctions in money attitudes encourage the perception of individual's income, and FWB (Gasiorowska, 2014b; 2015; Tang et al., 2013; Tang et al., 2006; Wilhelm et al., 1993). Furthermore, money attitude becomes one of the significant indicators of FWB as expanded positive money attitude has significant effects on individuals' overall well-being, whereby it decreases social, and psychological pressures. It demonstrates that the person with positive money attitude stimulate the mortality salience on the perception of money (Zaleskiewicz et al., 2013) tend to accomplish the larger amount of income. A decent income has a noteworthy effect on financial satisfaction that lead to a superior FWB. Therefore, the hypothesis was accepted.

$\mathrm{H}_{5}$ : A significant difference exists between employees’ financial practices and FWB.

The Pearson's Correlation Coefficient was applied to find out the association between financial practices, and employees' FWB, and the results were clearly lined with the research hypothesis, because a positive association was observed between financial practices, and FWB $(r=0.414, n=554, p=0.000)$. More familiar with financial practices were linked with higher percentages of FWB. Past studies have shown a noteworthy connection between financial practices, and FWB (Gutter \& Copur, 2011). Further, O'Neill et al. (2005) pointed out that a higher number of positive financial behaviours, and financial practices were associated with a higher FWB levels. Kim et al. (2003) showed that inappropriate financial management practices were negatively linked to wellness, and Worthy et al. (2010) specified that problematic financial behavioural practices of university undergraduates might influence on the future FWB of them. Hence, the hypothesis was accepted.

$\mathrm{H}_{6}$ : A significant difference exists between employees' self-efficacy and FWB.

Pearson's correlation coefficient was utilized to analyse the association between self-efficacy, and FWB of employees. The results are compatible to the research hypothesis, because a positive correlation was indicated between self-efficacy, and FWB $(\mathrm{r}=0.397, \mathrm{n}=554, \mathrm{p}=0.000)$. The higher level of SWB was shown by the persons with stronger general self-efficacy (Yuehua \& Song, 2004). Furthermore, the results of Siu et al., (2007) confirmed that general self-efficacy plays a vital role in workers' well-being in the collectivist society of China. In Sahu, and Rath's (2003) study, a solid connotation was found between selfefficacy, and FWB. In contrast, an employee with high self-efficacy has the ability to uplift the level of their FWB. Hence, the hypothesis was acknowledged.

$\mathrm{H}_{7}$ : A significant difference exists between employees' emotion coping and FWB.

Pearson's correlation coefficient demonstrated in Table 4 revealed that opposing idea to the research hypothesis, because a negative association was indicated between emotion coping, and FWB ( $\mathrm{r}=-0.091, \mathrm{n}=554, \mathrm{p}=0.034)$. According to Kohn (1996, p. 186) "Emotion-focused coping, by contrast, has consistently proven to be associated with negative adaptation". People who are accompanying with negative adaptations, negatively effect on FWB. Therefore, emotion coping would be negatively affected on FWB level of a person. Therefore, the hypothesis was accepted. 


\subsection{The determinants of FWB among employees.}

The contributory influences of FWB was analysed using multiple regression analysis. The gender (dummy variable), marital status (dummy variable), household income, money attitude, financial practices, self-efficacy, and emotion coping were considered as the independent variables for the study. The tolerance, and VIF have been studied and the values did not violate the assumption. Therefore, multiple regression analysis can be performed.

\subsection{Multivariate results}

\section{Table 5}

Results of multiple regression analysis for the determinants of FWB

\begin{tabular}{lcccc}
\hline Variable & $\mathrm{b}$ & $\mathrm{Beta}$ & $\mathrm{t}$ & $\mathrm{Sig}$. \\
\hline Money attitude & 1.339 & 0.235 & 5.107 & $0.000^{* *}$ \\
Financial practices & 0.566 & 0.324 & 8.273 & $0.000^{* *}$ \\
Self-efficacy & 0.573 & 0.203 & 4.568 & $0.000^{* *}$ \\
Emotion coping & -0.398 & -0.110 & -2.934 & $0.003^{* *}$ \\
\hline
\end{tabular}

$\mathrm{R}=.571 ; \mathrm{R} 2=.326 ;$ Adjusted $\mathrm{R} 2=.320 ; \mathrm{F}=61.245 ;$ Sig. $\mathrm{F}=.000$

$* * p<.01$

$\mathrm{H}_{8}$ : Money attitude, financial practices, self-efficacy, and emotion coping are significant determinants of FWB of employees.

The multiple regression results of the study for the four factors are displayed in Table 5, and clarified $32 \%$ of the variance of FWB. It could be explained that the capability of different other elements that explain the rest of the variance of FWB of the selected employees. The Beta values of the Table 5 demonstrates the percentage of involvement of independent variables to describe the dependent variable, and the significant value may describe whether the effects of independent variables are significant or not on the prediction of dependent variable. According to the obtained results, all four independent variables; financial practices, self-efficacy, money attitude, and emotion coping were significant. Therefore, the hypothesis was accepted and financial practices were the highest forecaster of FWB among employees in Malaysia (Beta=0.324). The results also have shown that money attitude, financial practices, and self-efficacy were positively predicting FWB, and meanwhile, emotion coping was negatively predicting the FWB. Furthermore, employees with greater level of money attitude, financial practices, and self-efficacy have greater FWB, conversely with higher emotion coping level, a lower FWB was observed. In addition, some positive money attitudes may support a person to succeed his/her financial status via budgeting, and intensify their determinations to earn better earnings, and secure their upcoming financial requirements. On the contrary, emotion coping was found to be negatively linked with FWB, because emotion-focused coping approaches wish to diminish, and accomplish the strength of the negative, and stressful emotions that a stressful situation has caused rather than solving the challenging situation itself. Beta values were indicated that, financial practices become the greatest predictor on FWB, and followed by money attitude, self-efficacy, and emotion coping.

\section{Conclusion and Implications}

In this study, the contributory factors of FWB among employees in Malaysia were investigated using multiple regression analysis. The aftereffects of the current study offer numerous key understandings. First, the outcomes proposed that the employees required to display necessary financial practices for example, savings, cash, and credit managing, and so on to become financially healthy. FWB is expressed as "high" if the employees have well financial behaviours, and positive financial attitudes. That is reliable with prior examinations (Shim et al., 2009; Xiao et al., 2009), and it was revealed that the effect of positive financial behaviours on FWB was positive. It has specified that employees who have positive financial behaviours such as saving, budgeting, not carrying out any risky credit card behaviours, and less prone to compulsive buying, significantly expanded the FWB. It means that the great financial behaviours are significant parts, because they determine the possible alterations in FWB (Joo, 2008). Xiao et al., (2009) likewise have shown that proper financial strategies in money managing, credit card managing, and saving were positively associated with the FWB. Therefore, financial education programs will be recommended to uplift positive financial practices in order to improve the well-being of employees directly.

Second, a positive money attitudes help people be cautious in expenditures via budgeting, and planning for their upcoming financial necessities. Further, it obviously demonstrates the influence of attitudes towards money on the association between subjective, and objective indicators of wealth of the employees in Malaysia. Third, the results have supported to the positive association between the general self-efficacy, and FWB. The outcome is validated by past findings (Chen et al., 2001; Judge \& Bono, 2001). People with lower dimensions of self-efficacy demonstrated to a higher degree of decreasing in mental wellbeing than those with higher level of self-efficacy, as pressure levels expanded. In this manner, general self-efficacy assumes a significant job in FWB (Siu et al., 2007). As clarified by Schaubroeck, and Merritt (1997), job control alleviates the impacts of difficulties on anxieties among people with great self-efficacy, and that would have pressure improving impacts among those with low self-efficacy. Therefore, improving the self-efficacy levels in employees are important to increase the work place productivity as well as their well-being. 
Fourth, the outcomes demonstrated that expanded emotion coping has a negative association with the FWB of the Malaysian employees. But, Por et al., (2011) suggested that increased emotion coping was helped to the student nurses to manage pressure which intern enhances their subjective well-being. Further, the coping responses are important to self-improvement by supporting emotional well-being (Brougham et al., 2009). Therefore, the current study outcomes are inconsistent with some of the previous studies. The outcomes of the research could attend as guidelines to the government, especially for the Economic Planning Unit (EPU), in planning economic policies. Further, it is imperative to elevate financial education to employees, because it can deliver the essential skills, knowledge, and tools for them to take knowledgeable conclusions with selfconfidence. Therefore, this activity will feature the significance of financial practices as essential talents for workers to train them on how to improve, and continue well financial behaviour, and practices for FWB. Endeavours to give quality financial practices to Malaysians might support to increase purchasers' comprehension of their FWB, hence they can set up, and accomplish individual financial goals, and develop financial security.

All things considered, employer-sponsored work environment financial counselling, and education might turn into a solid deal for the future. The financial knowledge improving projects, for example, cluster workshops on appropriate financial practices or individual programs between financial counsellors, and employees, might help employees effectively. Borden et al., (2008) presumed that successful financial training given in a workshop set-up might be both advantageous, and open to a more extensive group of employees. It might be compelling in encouraging FWB in Malaysian employees. Decreased financial stress might assist employees to be more focused at the work environment, thus benefiting companies.

To summarize, this study gives extra knowledge concerning the effect of financial practices, money attitudes, self-efficacy and emotion coping on employees' FWB. It appears that it is important to study the instrumental, and affective aspects of financial practices, self-efficacy, money attitudes, and emotion coping distinctly, as their effect on the connection between subjective, and objective indicators of wealth varies. All things considered, more future studies will be expected to recreate outcomes presented in this paper in various samples and cultures, and with dissimilar measures of FWB, and financial practices, self-efficacy, money attitudes, and emotion coping to improve our comprehension on the current study.

\section{Acknowledgement}

The authors wish to express their gratefulness to the Ministry of Education Malaysia (Fundamental Research Grant Scheme (5524875) for funding this study entitled "Development of a financial vulnerability model for Malaysian households towards achieving financial sustainability".

\section{References}

A survey of adults in Australia. (2018). Financial wellbeing. ANZ Banking Group Limited.

Arendt, S., \& Brettel, M. (2010). Understanding the influence of corporate social responsibility on corporate identity, image, and firm performance. Management Decision, 48(10), 1469-1492.

Bandura, A. (1977). Self-efficacy: Toward a unifying theory of behavioral change. Psychological Review, 84, $191-215$.

Bandura, A. (1986). Social foundations of thought and action: A social cognitive theory. Englewood Cliffs, NJ: Prentice Hall. Bandura, A. (1997). Self-efficacy: The exercise of control. New York: Freeman.

Borden, L. M., Lee, S., Serido, J., \& Collins, D. (2008). Changing college students' financial knowledge, attitudes and behavior through seminar participation. Journal of Family and Economic Issues, 29, 23-40.

Bowman, D., Banks, M., Fela, G., Russell, R., \& de Silva, A. (2016). Understanding financial wellbeing in times of insecurity. Retrieved on 25/08/2019 from Brotherhood of St Laurence, Fitzroy, Australia: http://library.bsl.org.au/jspui/bitstream/1/9423/1/Bowman_etal_Understanding_financial_wellbeing_2017.pdf

Brougham, R. R., Zail, C. M., Mendoza, C. M., \& Miller, J. R. (2009). Stress, sex differences, and coping strategies among college students, Current Psychology, 28, 85-97.

Cochran, P. L., \& Wood, R. A. (1984). Corporate social responsibility and financial performance. Academy of Management Journal, 27(1), 42-56.

Consumer Financial Protection Bureau (CFPB). (2015). Consumer Response Annual Report.

Diener, E., Diener, M., \& Diener, C. (1995). Factors predicting the subjective well-being of nations. Journal of Personality and Social Psychology, 69, 851-864.

Doyle, D., \& Forehand, M. J. (1984). Life satisfaction and old age: A re-examination. Research on Aging, 6, $432-448$.

Falahati, L., \& Paim, L. H. (2011). Gender differences in financial well-being among college students. Australian Journal of Basic and Applied Sciences, 5(9), 1765-1776.

Falahati, L., \& Sabri, M.F. (2015). An exploratory study of personal financial well-being determinants: Examining the moderating effect of gender. Asian Social Science, 11(4), 33-42.

Farrell, L., Fry, T. R. L., \& Risse, L. (2016). The significance of financial self-efficacy in explaining women's personal finance behavior. Journal of Economic Psychology, 54, 85-99.

Fox, J. J., \& Bartholomae, S. (2008). Evaluation of the 2008 Women \& Money Program. Retrieved on 25/08/2019 from http://www.osu.edu/search/index.php. 
Friedman, M. (1957). A Theory of the Consumption Function. In M. Friedman (Eds.), The Permanent Income Hypothesis (pp. 20 - 37). Princeton University Press, ISBN 978-0-691-04182-7.

García de Leaniz, P. M., \& Del Bosque Rodríguez, I. (2015). Exploring the antecedents of hotel customer loyalty: A social identity perspective. Journal of Hospitality Marketing \& Management, 24(1), 1-23.

Gasiorowska, A. (2014b). The relationship between objective and subjective wealth is moderated by financial control and mediated by money anxiety. Journal of Economic Psychology, 43, 64-74.

Gasiorowska, A. (2015). The impact of money attitudes on the relationship between income and financial satisfaction. Polish Psychological Bulletin, 46(2), 197-208.

George, L. K. (1992). Economic status and subjective well-being: A review of literature and an agenda for future research. In N. E. Cutler, D. W. Gregg, \& M. P. Lawton (Eds.), Aging, money, and life satisfaction: Aspects of financial gerontology (pp. 69-99). New York: Springer.

Godwin, D. D. (1996). Family finance and marital happiness. Paper presented at the Eastern Family Economics and Resource Management Conference in Tuscaloosa, AL.

Gray, J. S. (1997). The fall in men's return to marriage: Declining productivity effects or changing selection? Journal of Human Resources, 32, 481-504.

Gutter, M., \& Copur, Z. (2011). Financial behaviours and financial well-being of college students: evidence from a National Survey. Journal of Family and Economic Issues, 32, 699-714.

Hadar, L, Sood, S., \& Fox, C. R. (2013). Subjective knowledge in consumer financial decisions, Journal of Marketing Research, 50(3), 303-316.

Headey, B., Veenhoven, R., \& Wearing, A. (1991). Top-down versus bottom-up theories of subjective well-being. Social Indicators Research, 24, 81-100.

Hira, T. K., \& Mugenda, O. (1999b). The relationships between self-worth and financial beliefs, behavior, and satisfaction. Journal of Family and Consumer Sciences, 91(4), 76.

Joo, H., \& Grable, J. E. (2004). An exploratory framework of the determinants of financial satisfaction. Journal of Family and Economic Issues, 25, 25-50.

Joo, S. (2008). Personal financial wellness. In J.J. Xiao (Ed.), Handbook of consumer finance research (pp. 21-33). New York: Springer.

Kamaruddin, A. R., \& Mokhlis, H. (2003). Consumer socialization, social structural factors and decision making styles: a case study of adolescents in Malaysia. International Journal of Consumer Studies, 27(2), 145-156.

Kammeyer-Mueller, J. D., Judge, T. A., \& Brent A. Scott (2009), The role of core self-evaluations in the coping process, Journal of Applied Psychology, 94(1), 177-95.

Kim, J., Garman, E. T., \& Sorhaindo, B., (2003). Relationships among credit counselling clients' financial well-being, financial behaviors, financial stressor events, and health. Financial Counselling and Planning, 14, 75-87.

Korenman, S., \& Neumark, D. (1991). Does marriage really make men more productive? Journal of Human Resources, 26, 282-307.

La Barbera, P. A., \& Gürhan, Z. (1997). The role of materialism, religiosity, and demographics in subjective well-being. Psychology \& Marketing, 14, 71-97.

Lazarus, R. S., \& Folkman, S. (1984). Stress, appraisal, and coping. New York: Springer.

Mack, J., \& Lansley, S. (1985). Poor Britain. George Allen \& Unwin (Publishers) Ltd, 40 Museum Street, London WC1A $1 \mathrm{LU}, \mathrm{UK}$.

Mahdzan, N. S., Zainudin, R., Sukor, M. E. A., Zainir, F., \& Ahmad, W. M. W. (2019). Determinants of subjective financial well-being across three different household income groups in Malaysia. Social Indicators Research, 143, 1-28.

Masud, J., Rahim, H. A., Paim, L. H., \& Britt, S. (2004). Financial behavior and problems among university students: need for financial education. Journal of Personal Finance, 3(1), 82-96.

Meghir, C. (2004). A retrospective on Friedman's Theory of Permanent Income (PDF). Retrieved on 28/08/2019 from https://onlinelibrary.wiley.com/doi/full/10.1111/j.1468-0297.2004.00223.x.

Nickerson, C., Schwarz, N., \& Diener, E. (2007). Financial aspirations, financial success, and overall life satisfaction: who? and how?. Journal of Happiness Studies, 8(4), 467-515.

O’Neill, B., Xiao, J. J., Sorhaindo, B., \& Garman, E. T. (2005). Financial distressed consumers: Their financial practices, financial well-being, and health. Financial Counseling and Planning, 16(1), 73-87.

Ouweneel, E., Schaufeli, W. B., \& Blanc, P. M. L. (2013). Believe, and you will achieve: Changes over time in self-efficacy, engagement, and performance. APPLIED Psychology: Health and Wellbeing, 5(2), 225-247.

Por, J., Barriball, L., Fitzpatrick, J., \& Roberts, J. (2011). Emotional intelligence: its relationship to stress, coping, well-being and professional performance in nursing students. Nurse education today, 31(8), 855-860

Pritchard, M. E., Wilson, G. S., \& Yamnitz, B. (2007). What predicts adjustment among college students?: A longitudinal panel study. Journal of American College Health, 56(1), 15-21.

Sabri, M. F., MacDonald, M., Hira, T. K., \& Masud, J. (2010). Childhood consumer experience and the financial literacy of college students in Malaysia. Family \& Consumer Sciences Research Journal, 38(4), 455- 467.

Sabri, M. F., \& Zakaria, N. F. (2015a). The influence of financial literacy, money attitude, financial strain and financial capability on young employees' financial well-being. Pertanika Journal of Social Sciences and Humanities, 23(4), 827848. 
Sabri, M. F., \& Zakaria, N. F. (2015b). Financial well-being among young employees in Malaysia. In Z. Copur (Ed.), Handbook of research on behavioral finance and investment strategies: Decision making in the financial industry (pp. 221-235). Hershey,USA: IGI Global.

Sahu, F. M., \& Rath, S. (2003). Self-efficacy and well-being in working and non-working women: The moderating role of involvement. Psychology Developing Societies, 15, 187-200.

Schaubroeck, J., \& Merritt, D.E. (1997). Divergent effects of job control on coping with work stressors: The key role of selfefficacy. Academy of Management Journal, 40, 738-754.

Scheier, M. F., Carver, C. S., \& Bridges, M. W. (1994). Distinguishing optimism from neuroticism (and trait anxiety, selfmastery, and self-esteem): A reevaluation of the Life Orientation Test. Journal of Personality and Social Psychology, 67(6), 1063-1078.

Shim, S., Xiao, J. J., Barber, B. L., \& Lyons, A. C. (2009). Pathways to life success: A conceptual model of financial wellbeing for young adults. Journal of Applied Developmental Psychology, 30, 708-723.

Siu, O., Lu, C., \& Spector, P. E. (2007). Employees' well-being in greater China: The direct and moderating effects of general self-efficacy. Applied Psychology: An International Review, 56(2), 288-30.

Sohn, S. H., Joo, S. H., Grable, J. E., Lee, S., \& Kim, M. (2012). Adolescents' financial literacy: The role of financial socialization agents, financial experiences, and money attitudes in shaping financial literacy among South Korean youth. Journal of Adolescence, 35(4), 969-980.

Stajkovic, A. D. \& Luthans, F. (1998). Self-efficacy and work-related performance: A meta-analysis. Psychological Bulletin. $2(2), 240-261$.

Tang, T. L. P., Luna-Arocas, R., Pardo, I., \& Tang, T. L. N. (2013). Materialism and the bright and dark sides of the financial dream in Spain: The positive role of money attitudes-the Matthew effect. Applied Psychology: An International Review.

Tang, T. L. P., Tang, T. L. N., \& Homaifar, B.Y. (2006). Income, the love of money, pay comparison, and pay satisfaction: Race and gender as moderators. Journal of Managerial Psychology, 21, 476-491.

Theodos, B., Kalish, E., McKernan, S. M., \& Ratcliffe, C. (2014). Do financial knowledge, behavior, and well-being differ by gender? Washington, DC: FINRA Investor Education Foundation.

Van-Praag, B. M. S., Frijters, P., \& Ferer-i-Carbonell, A. (2003). The anatomy of subjective well-being. Journal of Economic Behavior and Organization, 51, 29-49.

Veenhoven, R. (1991). Questions on happiness: Classical topics, modern answers, blind spots. In F. Strack, M. Argyle, \& N. Schwarz (Eds.), Subjective well-being: An interdisciplinary perspective (pp. 7-26). Elmsford, NY: Pergamon Press.

Verwijmerena, P., \& Derwall, J. (2010). Employee well-being, firm leverage, and bankruptcy risk. Journal of Banking \& Finance, 34(5), 956-964.

Vlachos, P. A., Tsamakos, A., Vrechopoulos, A. P., \& Avramidis, P. K. (2009). Corporate social responsibility: Attributions, loyalty, and the mediating role of trust. Journal of the Academy of Marketing Science, 37(2), 170-180.

Vosloo, W., Fouché, J., \& Barnard, J. (2014). The relationship between financial efficacy, satisfaction with remuneration and personal financial well-being. International Business \& Economics Research Journal, 13(6), 1455-1470.

Wilhelm, M. S., Varcoe, K., \& Fridrich, H. A. (1993). Financial satisfaction and assessment of financial progress: Importance of money attitudes. Financial Counseling and Planning, 4, 181-199.

Worthy, S. L., Jonkman, J., \& Pike, L. B. (2010). Sensation-seeking, risk-taking, and problematic financial behaviors of college students. Journal of Family and Economic Issues, 31, 161-170.

Xiao, J. J., Shim, S., Barber, B., \& Lyons, A. (2007). Academic success and well-being of college students: financial behaviours matter. (Technical Report) TCAI, University of Arizona.

Xiao, J. J., Tang, C., \& Shim, S. (2009). Acting for happiness: Financial behavior and life satisfaction of college students. Social Indicators Research, 92, 53-68.

Xiao, J. J., Tang, C., Serido, J., \& Shim, S. (2011). Antecedents and consequences of risky credit behavior among college students: Application and extension of the theory of planned behaviour. Journal of Public Policy and Marketing, 30(2), 239-245.

Yuehua, O. \& Song, S. (2004). A study on general self-efficacy and subjective well-being of low SES-college students in a Chinese university. College Student Journal, 38(4), 637-649.

Zaleskiewicz, T., Gasiorowska, A., Kesebir, P., Luszczynska, A., \& Pyszczynski, T. (2013). Money and the fear of death: The symbolic power of money as an existential anxiety buffer. Journal of Economic Psychology, 36, 55-67.

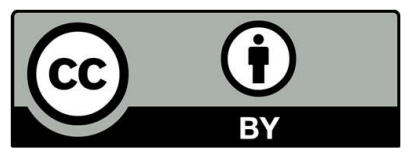

(C) 2020 by the authors; licensee Growing Science, Canada. This is an open access article distributed under the terms and conditions of the Creative Commons Attribution (CC-BY) license (http://creativecommons.org/licenses/by/4.0/). 